\title{
ENTREPRENEURIAL EDUCATION CONFERENCE PROCEEDINGS: A RHETORICAL MOVES ANALYSIS OF ABSTRACTS
}

\author{
Harison Mohd Sidek \\ Associate Prof., Universiti Sains Islam Malaysia, MALAYSIA, harison@usim.edu.my
}

\begin{abstract}
The first impression of an academic paper lies in its abstract because it provides the readers with an overview of the quality, relevancy and significance of the paper. Such first overall impression may determine the chances of the full paper being read or simply eliminated; which reader's decision has an impact on the author's opportunity either for his work to be cited and disseminated or disregarded. Therefore, it is critically important for academics at higher institutions to be able to present the summary of their works in the most comprehensive, systematic, clear and effective manner; one of the ways is by using the essential rhetorical moves framework as a guideline for abstract writing. The purpose of the present study was to analyze whether or not entrepreneurial educators include essential rhetorical moves in their conference proceedings abstracts using the revised model of Hyland's (2000) rhetorical moves. In addition, the study also examined the types of rhetorical moves sequence presented in the selected abstracts. Purposive sampling was used for data collection. Hyland's (2000) five-moves classification was revised and expanded to include the sixth rhetorical move labeled as Implications of which modification results in a six-moves classification. The six rhetorical moves in the revised model were used as the coding in analyzing the moves structure of the selected abstracts and types of sequence. The data were analyzed using manifest and latent content analyses. The findings reveal that only one abstract satisfies the six rhetorical moves while the other abstract contains only parts of the rhetorical moves with the types of moves sequence being highly varied. The study concludes that while academics do include the essential rhetorical moves when presenting their abstracts, in majority, they are still lacking of awareness in what an abstract should be. The implications of the findings were discussed in terms of awareness-raising amongst academics concerning the importance of producing an abstract that is comprehensive, systematic, clear and effective.
\end{abstract}

Keywords: Abstract, academics, academic writing, rhetorical moves, conference proceedings

\section{INTRODUCTION}

Academic writing involves many genres. Each genre requires academics to have specific writing skills. For example, the writing skills required for writing an academic book are different than the skills required for writing a research report. The ability to conduct a quality research does not translate to the ability to write a quality report. An academic needs to have the ability to write well in order to present their research report in the most effective way. Writing an abstract is part of writing a research report. Abstract is an important part of a research report of which its presentation plays a major role in the fate of the research being read in full or 
simply disregarded. Thus, the competency in writing a quality abstract becomes imperative because it provides an alluring drive for readers to consider reading the entire research as worthwhile and beneficial.

\section{LITERATURE REVIEW}

With regards to abstract analysis, many studies had been carried out of various natures (e.g., Bunton, 2002; Kwan, 2006; Bunton, 2005; Bonn \& Swales, 2007; Cross \& Oppenheim, 2006; Hongwei Ren \& Yuying Li, 2011; Huckin, 2006; Hyland, 2000; Lau, 2004; Lores, 2004; Lores, 2004; Pho, 2008; Samraj, 2005; Sidek, et al., 2016; Santos, 1996; Stotesbury, 2003; Suntara \& Usaha, 2013). Most of past studies focused on investigating abstracts in theses compared to past studies that examined abstracts of conference proceeding. This shows that studies on abstracts for conference proceedings are still very few. In the study of Sidek et al. (2016), they found that academics in the field of linguistics and language education who participated in the selected conference demonstrated lacking of the inclusion of rhetorical moves causing their abstracts to be presented in an incomplete way and thus affects their effectiveness. In the same study, the researchers also reported that the sample academics juggled the rhetorical moves sequence in an irregular way. Since studies on abstracts for conference proceedings are rather scarce, it is inconclusive if such an abstract writing behaviour phenomenon only occurred amongst academics in the language-related studies domain or perhaps in other educational domains as well.

Insofar, based on mainstream publications, Sidek et al. (2016) seems to be the only study that had examined abstracts for conference proceedings. Nonetheless, Sidek et al. (2016) only studied abstracts in linguistics and language education conference proceedings. Therefore, the current study attempted to examine the rhetorical moves in abstracts within the domain of entrepreneurial education, a cutting edge educational domain that concerns with embedding entrepreneurship in all educational disciplines. Abstracts to present reports on studies conducted in such an important domain should be carefully designed to ensure that beneficial studies are not being overlooked due to poor abstract presentation.

\section{THEORETICAL FRAMEWORK}

The current study is a replicated study on abstract analysis for conference proceedings following the framework of Sidek et al.'s (2016) study. Sidek et al. (2016) examined the rhetorical moves in abstract using the theoretical framework proposed by Hyland (2000). This theoretical framework is the synthesized framework of various classifications found in abstracts. Hyland (2000) developed a five-rhetorical moves structure. The rhetorical move framework comprises the structures of Introduction, Purpose, Method, Product and Conclusion. There are other proposed moves (e.g., Huckin, 2006; Lores, 2004; Melander et al., 1997; Samraj, 2005; Santos, 1996), which are subsumed in Hyland's (2000) rhetorical moves for abstracts framework. Figure 1 presents the five-rhetorical moves framework of Hyland (2000).

Figure 1: Hyland's (2000) Five-Rhetorical Moves Structure

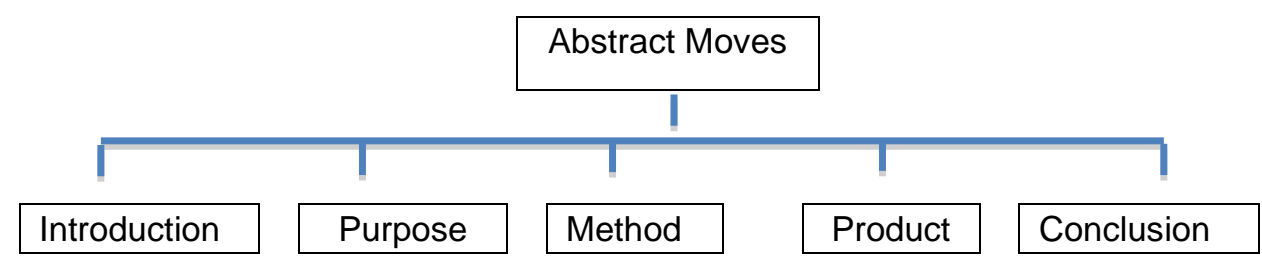

Sidek et al. (2016) used Hyland's (2000) rhetorical moves structure but with the addition of a dichotomy in the Introduction structure. Sidek et al. (2016) introduced two sub-structures of Hyland's (2000) Introduction structure; the Problem and Theory structures. Figure 2 presents the six-rhetorical moves framework of Sidek et al. (2016).

Figure 2: Sidek et al.'s (2016) Six-Rhetorical Moves Structure

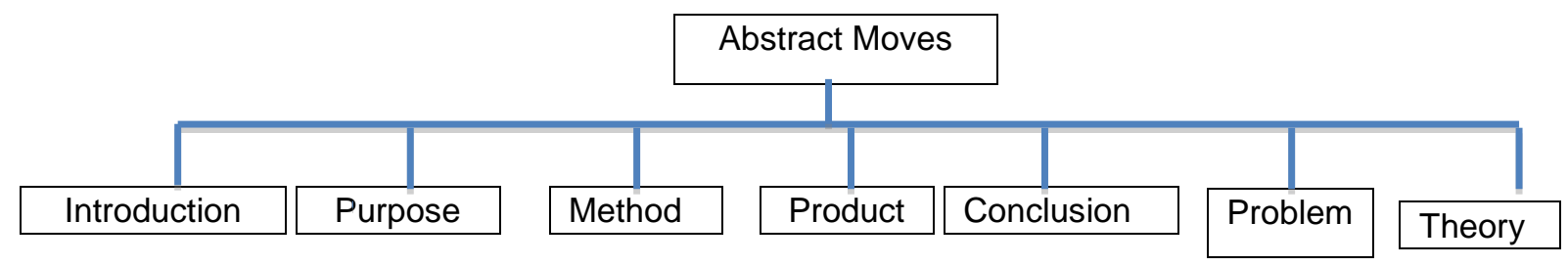


Based on the preliminary review of the entrepreneurial abstracts for the current study, the entrepreneurial educators seemed to commonly present the Introduction structure in the form of Problem rather than Theory unlike in the language and education abstracts examined by Sidek et al. (2016). Due to such nature, Sidek et al.'s (2016) dichotomized Introduction structure is ,therefore, considered as a subsumed of Hyland's (2000) Introduction structure. Therefore, using the Introduction structure as in Hyland's (2000) rhetorical moves model was deemed for appropriate for the present study. Nonetheless, the preliminary review of the selected abstracts indicated that there is an additional structure that is significant for abstracts on entrepreneurship due to the nature of the discipline, which is the Implication structure. Figure 3 presents the revised sixrhetorical moves framework of Sidek et al. (2016).

Figure 3: Sidek et al.'s (2016) Six-Rhetorical Moves Structure

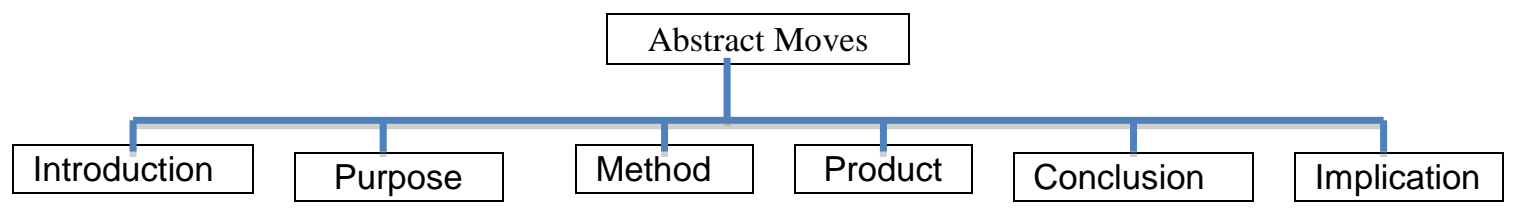

The theoretical framework of rhetorical moves structure in Figure 3 serves as the theoretical framework for the present study.

\section{METHODOLOGY}

The purpose of the present study was to analyze whether or not entrepreneurial educators include essential rhetorical moves in their conference proceedings abstracts using the revised model of Hyland's (2000) rhetorical moves. In addition, the study also examined the types of rhetorical moves sequence presented in the selected abstracts. The following research questions guided the study.

Research Question 1: Do the abstracts in entrepreneurship education conference proceedings include the essential rhetorical moves?

Research Question 2: What are the types of rhetorical moves sequence used in entrepreneurship education conference proceedings abstracts?

\subsection{Research Context}

The research context for this study was an entrepreneurial educators conference. The conference was specifically organized for entrepreneurial educators to present their entrepreneurship-related educational studies. The participants of the conference comprised of educators from various educational disciplines who have conducted studies, which incorporated the element of entrepreneurship into their discipline specifics. The presenters were a mixture of educators from public and private universities as well as college communities. The papers presented at the conference were in the forms of theoretical papers, conceptual papers and empirical-based papers.

\subsection{Instrument}

The selected conference abstract book was used as a source of data for the study. The abstract book comprises abstracts that were accepted for and presented at the conference. The abstracts were numbered by a computer system as it was received by the system. The abstracts were edited by experts in entrepreneurship as stated on the cover page of the abstract book.

\subsection{Samples}

The abstracts selected for this study were part of proceedings presented at an entrepreneurial conference. The entrepreneurial educators come from diverse backgrounds in science and social science fields. The abstract book comprises 24 abstract on entrepreneurship on diverse subject matters. All abstracts presented in the abstract book were included in the study since they are empirical in nature and as such the revised six-moves rhetorical classification is applicable to the selected abstracts.

\subsection{Data Collection}

The abstracts in conference proceedings from the selected conference were reviewed according to the revised six-moves classification of rhetorical moves. Unlike in the study of Sidek et al.'s (2016) that dissected Hyland's (2000) Introduction move into Problem and Theory, the current study excluded such dichotomy. Therefore, the abstracts were examined and categorized only into the six moves classification; Introduction, Purpose, Method, Product, Conclusion and Implication. The Implication move was included as part of the 
revision of Hyland's (2000) model because including the implications of the study provides the abstract readers a brief insight into the usability of the findings and how the findings lend benefits outside the research boundary. Hence, readers might be able to gauge the significance of the study to them. The tabulation of the moves classification was validated and yielded a validity index of 0.87 .

\subsection{Data Analysis}

In order to answer Research Question 1, the selected abstract were analysed by tabulating the moves structure of each abstract according to the revised six-moves classification as the tabulation in Sidek et al.'s (2016) study. The sample of tabulation is presented in Table 1.

Table 1: Sample of Six Rhetorical Moves Tabulation

\begin{tabular}{|c|c|c|c|c|}
\hline Abstracts & Included Moves & $\%$ & Excluded Moves & $\%$ \\
\hline 1 & Met; Pro; Con; Imp & 67 & Int; Pur & 33 \\
\hline 2 & Int; Pur; Met; Pro; Imp & 83 & Con & 17 \\
\hline 3 & Int; Met; Pro & 50 & Pur; Con; Imp & 50 \\
\hline 4 & Int; Pur & 33 & $\begin{array}{c}\text { Pur; Pro; Met; Con; } \\
\text { Imp }\end{array}$ & 63 \\
\hline
\end{tabular}

Upon completing the tabulation, the tabulated data for each abstract were dichotomized into two categories; Included Moves and Excluded Moves as shown in Table 2. For each abstract, the percentages of Included Move and Excluded Moves were calculated against the six rhetorical moves scale.

Table 2: Sample of Included and Excluded Rhetorical Moves Analysis

\begin{tabular}{|c|c|c|c|c|c|c|}
\hline Abstract/ Moves & Introduction & Purose & Method & Product & Conclusion & Implication \\
\hline 1 & $/$ & $/$ & $/$ & $/$ & $/$ & $/$ \\
\hline 2 & $/$ & $\mathrm{x}$ & $/$ & $/$ & $/$ & $\mathrm{x}$ \\
\hline 3 & $/$ & $/$ & $/$ & $/$ & $\mathrm{x}$ & $/$ \\
\hline 4 & $/$ & $/$ & $/$ & $/$ & $/$ & $\mathrm{x}$ \\
\hline 5 & $\mathrm{x}$ & $/$ & $/$ & $/$ & $/$ & $/$ \\
\hline 6 & $\mathrm{x}$ & $\mathrm{x}$ & $/$ & $/$ & $\mathrm{x}$ & $/$ \\
\hline 7 & $\mathrm{x}$ & $/$ & $/$ & $/$ & $/$ & $\mathrm{x}$ \\
\hline 8 & $/$ & $/$ & $\mathrm{x}$ & $/$ & $\mathrm{x}$ & $\mathrm{x}$ \\
\hline
\end{tabular}

To analyse the types of rhetorical move sequence in Research Question 2, the data were analysed by recording the rhetorical moves that appear in the abstracts as proposed in the revised six-moves classification model.

\section{FINDINGS}

The findings are presented in two parts; i) Rhetorical moves inclusion and exclusion and ii) Rhetorical moves sequence model. The first part presents the findings for Research Question 1 while rhetorical moves sequence model presents the findings for Research Question 2.

\subsection{Rhetorical Moves Inclusion/Exclusion Analysis}

Table 3 shows the overall view of the included and excluded rhetorical moves for the 24 abstracts.

Table 3: Overall View of Included and Excluded Rhetorical Moves

\begin{tabular}{|c|c|c|c|c|}
\hline Abstract & Included Moves & $\%$ & Excluded Moves & $\%$ \\
\hline 1 & Met; Pro; Con; Imp & 67 & Int; Pur & 33 \\
\hline 2 & Int; Pur; Met; Pro; Imp & 83 & Con & 17 \\
\hline 3 & Int; Met; Pro & 50 & Pur; Con; Imp & 50 \\
\hline 4 & Int; Pur & 33 & Pur; Pro; Met; Con; Imp & 67 \\
\hline 5 & Int; Pur; Met; Pro & 67 & Con; Imp & 33 \\
\hline 6 & Int; Met; Pro; Imp & 67 & Pur; Con & 33 \\
\hline 7 & Int; Pur; Met; Pro; Con; Imp & 100 & - & 0 \\
\hline 8 & Int; Pur; Met; Pro & 67 & Con; Imp & 33 \\
\hline 9 & Int; Pur; Met; Pro; Con & 83 & Imp & 17 \\
\hline
\end{tabular}


IJASOS- International E-Journal of Advances in Social Sciences, Vol. III, Issue 9, December 2017

\begin{tabular}{|c|c|c|c|c|}
\hline 10 & Pur; Met; Pro; Imp & 67 & Int; Con & 33 \\
\hline 11 & Int; Met; Pro; Con & 67 & Pur; Imp & 33 \\
\hline 12 & Int; Pur; Met; Pro; Con & 83 & Imp & 17 \\
\hline 13 & Int; Pur; Met; Pro; Imp & 83 & Con & 17 \\
\hline 14 & Int; Pur; Met; Pro & 67 & Con; Imp & 33 \\
\hline 15 & Int; Met; Pro; Con & 67 & Pur; Imp & 33 \\
\hline 16 & Int; Pur; Met; Pro; & 67 & Con; Imp & 33 \\
\hline 17 & Pur; Met; Pro; & 50 & Int; Con; Imp & 50 \\
\hline 18 & Int; Pur; Met; & 50 & Pro; Con; Imp & 50 \\
\hline 19 & Int; Met & 33 & Pur; Pro; Con; Imp & 67 \\
\hline 20 & Int; Pur & 33 & Met; Pro; Con; Imp & 67 \\
\hline 21 & Pur; Met; Con & 50 & Int; Pro; Imp & 50 \\
\hline 22 & Int; Pur, Met; Con & 67 & Pro; Imp & 33 \\
\hline 23 & Pur; Met & 33 & Int; Pro; Con; Imp & 67 \\
\hline 24 & Int; Met; Pro & 50 & Pur; Con; Imp & 50 \\
\hline & Mean & 61.8 & & 38.2 \\
\hline
\end{tabular}

Key: Int=Introduction; Pur=Purpose; Met= Method; Pro=Product; Con=Conclusion; Imp=Implications

Table 3 shows that, on average, each abstract included only approximately $62 \%$ of the abstract rhetorical moves based on the six-moves rhetorical classification coding. On average, about $38 \%$ of the rhetorical moves were not included in the abstracts.

The overall results of the analyses of the rhetorical moves as presented in Table 3 were re-categorized into individual rhetorical move analysis as presented in Tables 4 to 9.

In terms of the Introduction move, Table 4 shows that 79 percent of the abstract included the Introduction move while 21 percent excluded this move.

Table 4: Introduction Rhetorical Move Analysis

\begin{tabular}{|c|c|}
\hline \multicolumn{2}{|c|}{ Introduction Move } \\
\hline Included (\%) & Excluded (\%) \\
\hline 79 & 21 \\
\hline
\end{tabular}

Table 5: Purpose Rhetorical Move Analysis

\begin{tabular}{|c|c|}
\hline \multicolumn{2}{|c|}{ Purpose Move } \\
\hline Included (\%) & Excluded (\%) \\
\hline 67 & 33 \\
\hline
\end{tabular}

Table 5 shows that 67 percent of the selected abstracts included the Purpose move and about 33 percent excluded the Purpose move.

Table 6: Method Rhetorical Move Analysis

\begin{tabular}{|c|c|}
\hline \multicolumn{2}{|c|}{ Method Move } \\
\hline Included (\%) & Excluded (\%) \\
\hline 96 & 4 \\
\hline
\end{tabular}

Table 6 exhibits that 96 percent of the entrepreneurial educators' abstracts included the Method move. Merely 4 percent of the abstracts excluded the Method move.

Table 7: Product Rhetorical Move Analysis

\begin{tabular}{|c|c|}
\hline \multicolumn{2}{|c|}{ Product Move } \\
\hline Included (\%) & Excluded (\%) \\
\hline 75 & 25 \\
\hline
\end{tabular}

In Table 7, 75 percent of the abstracts included the Product rhetorical move analysis. Twenty five percent of the abstract did not include the Product move. 
Table 8: Conclusion Rhetorical Move Analysis

\begin{tabular}{|c|c|}
\hline \multicolumn{2}{|c|}{ Conclusion Move } \\
\hline Included (\%) & Excluded (\%) \\
\hline 33 & 67 \\
\hline
\end{tabular}

As in Table 8, for the Conclusion rhetorical move analysis, only 33 percent of the abstracts included the Conclusion move while 67 percent of the abstracts were without the Conclusion move.

Table 9: Implication Rhetorical Move Analysis

\begin{tabular}{|c|c|}
\hline \multicolumn{2}{|c|}{ Implication Move } \\
\hline Included (\%) & Excluded (\%) \\
\hline 25 & 75 \\
\hline
\end{tabular}

As for the Implication rhetorical move analysis as shown in Table 9, the finding shows that the majority of the abstracts did not include the Implication move (75\%). Only 25 percent of the abstracts included the Implication move.

\subsection{Types of Rhetorical Moves Sequence}

This section presents the findings for Research Question 2. The findings are in the forms of overall analysis of the types of rhetorical moves model used in the selected abstracts. Table 10 presents the tabulation of rhetorical moves sequence.

Table 10: Types of Rhetorical Moves Sequence Tabulation

\begin{tabular}{|c|c|c|c|}
\hline $\begin{array}{c}\text { Abstract } \\
\text { Number }\end{array}$ & $\begin{array}{c}\text { Types of Rhetorical } \\
\text { Moves Sequence }\end{array}$ & $\begin{array}{c}\text { Abstract } \\
\text { Number }\end{array}$ & $\begin{array}{c}\text { Types of Rhetorical Moves } \\
\text { Sequence }\end{array}$ \\
\hline 1 & Met; Pro; Con; Imp & 13 & Int; Pur; Met; Pro; Imp \\
\hline 2 & Int; Pur; Met; Pro; Imp & 14 & Int; Pur; Met; Pro \\
\hline 3 & Int; Met; Pro & 15 & Int; Met; Pro; Con \\
\hline 4 & Int; Pur & 16 & Int; Pur; Met; Pro \\
\hline 5 & Int; Pur; Met; Pro & 17 & Pur; Met; Pro \\
\hline 6 & Int; Met; Pro; Imp & 18 & Int; Pur; Met \\
\hline 7 & $\begin{array}{c}\text { Int; Pur; Met; Pro; Con; } \\
\text { Imp }\end{array}$ & 19 & Int; Met \\
\hline 8 & Int; Pur; Met; Pro & 20 & Int; Pur \\
\hline 9 & Int; Pur; Met; Pro; Con & 21 & Pur; Met; Con \\
\hline 10 & Pur; Met; Pro; Imp & 22 & Int; Pur, Met; Con \\
\hline 11 & Int; Met; Pro; Con & 23 & Pur; Met \\
\hline 12 & Int; Pur; Met; Pro; Con & 24 & Int; Met; Pro \\
\hline
\end{tabular}

Key: Int=Introduction; Pur=Purpose; Met= Method; Pro=Product; Con=Conclusion; Imp=Implications

Table 10 shows that each abstract has its own unique type of abstract moves sequence with only one abstract (abstract 7) employs the sequence and inclusion of all abstract moves as proposed in the revised six-moves rhetorical classification. The other abstracts are presented with a wide range of arbitrary moves combinations.

\section{DISCUSSION}

The findings of this study show that approximately 96 percent of the abstracts examined in this study, excluded at least one rhetorical move. Only one abstract (abstract 7 ) included all moves. In this particular abstract, each rhetorical move is labelled explicitly as a marking of the different section of the abstract. Unless the author is interviewed, it is unclear whether the inclusion of all essential rhetorical moves in this particular abstract was due to the author's awareness of the rhetorical moves that should be included in the abstract or simply due to the transforming of those labels that appear in the full paper. Nonetheless, the abstract has all the moves and thus satisfied the six-moves coding classification of abstract rhetorical moves.

In terms of the findings of the Introduction, Purpose, Method and Product rhetorical moves, the majority of the selected abstracts included these moves with the percentage of inclusion being above the 60 percent. These findings suggest that the Introduction, Purpose, Method and Product rhetorical moves were considered as essential rhetorical moves to be included in the abstracts. Hence, it can be inferred that the 
IJASOS- International E-Journal of Advances in Social Sciences, Vol. III, Issue 9, December 2017

authors of the abstracts perceived the inclusion of these moves as conventional and not optional. Kanoksilapatham (2005) stated that when the inclusion of an abstract move is rated above 60 percent, such move can be considered as conventional rather than optional.

As for the Conclusion move, almost 88 percent of the abstract excluded the Conclusion move. It is a phenomenon of why the majority of the abstract authors seem to not consider the importance of providing a conclusion of their studies in the abstracts. When conclusion is not provided the authors leave the readers without any synthesis of what they have examined and analysed. Such behaviour becomes a phenomenon as with regards to the authors' awareness of the importance to include the Conclusion move as part of the elements that might enhance readers' interest to read their full papers. In addition, the Conclusion move also functions as a cue of the relevancy of the study to readers' search since an abstract plays a role as a screener (e.g., Hartley \& Benjamin, 1998; Huckin, 2006; Swales, 1990). A similar situation emerges for the Implication move in which 75 percent of the abstracts were written without the Implication move. When the implication of a study is excluded from an abstract, the significance of the study is not highlighted. A research is conducted to benefit or provide insights beyond the boundary of the research context itself. This is despite the notion that the Conclusion and Implication moves might be considered as optional in some disciplines (e.g., Suntara \& Usaha, 2013).

Besides the inclusion and exclusion of rhetorical moves, the findings on rhetorical moves sequence show that other than Abstract 7, the other abstracts are presented with a wide range of arbitrary moves sequence combinations. Two abstracts, abstract 9 and 12 followed Hyland's (2000) five-moves rhetorical sequence with the exclusion of the Implication move. Abstracts 2 and 13 also follow Hyland's (2000) five-moves, however, with the inclusion of the Implication move in replacement of the Conclusion move. Abstracts 4, 19, 20 and 23 only used two-moves rhetorical sequence, which abstract presentation is highly lacking in clarity due to the missing of the majority of the moves. Hence, such a rhetorical move sequence model can be considered as impractical and defeats the purpose of an abstract provision as a drive for the full text reading. The varied rhetorical moves sequence in the selected abstract can be of many reasons, one of which is the element of authors' awareness in abstract writing. However, since this study did not include interviewing the abstract authors, the underlying reasoning of the choice of the abstract rhetorical moves sequence selected by the abstract authors remains a grey area and yet a potential niche for future studies on abstract rhetorical moves.

\section{CONCLUSION}

The findings of the current study are in alignment with the findings of Sidek et al. (2016). Abstract writing is a skill that still needs to be trained and nurtured among academics regardless of academic disciplines. It is imperative that academics have the knowledge, expertise and awareness in writing an effective abstracts. Based on the findings of the present study and previous studies of a similar nature, the emphasis on producing a quality abstract should be enhanced in order to ascertain quality studies are being read. Otherwise, beneficial studies would be overlooked and regarded as irrelevant because of a poor misperception that is caused by an ineffective written abstract. Therefore, an awareness-raising effort needs to be made in assisting academics to write abstracts effectively for the purpose of effective knowledge dissemination.

\section{REFERENCE LIST}

Bonn, S. V., \& Swales, J. M. (2007). English and French journal abstracts in the language sciences: Three exploratory studies. Journal of English for Academic Purposes, 6(2), 93-108. http://dx.doi.org/10.1016/j.jeap.2007.04.001

Bunton, D. (2002). Generic moves in Phd thesis introductions. In J. Flowerdew (ed.) Academic Discourse.(pp.57-75). Lon: Longman.

Bunton, D. (2005). The structure of PhD conclusion chapters. Journal of English for Academic Purposes, 4, 207-224. 
IJASOS- International E-Journal of Advances in Social Sciences, Vol. III, Issue 9, December 2017

Cross, C., \& Oppenheim, C. (2006). A genre analysis of scientific abstracts. Journal of Documentation, 62(4), 428-446. doi:10.1108/00220410610700953, http://dx.doi.org/10.1108/00220410610700953

Hartley, J., \& Benjamin, M. (1998). An evaluation of structured abstracts in journals published by the British psychological society. British Journal of Educational Psychology, 68, 443-456. doi:10.1111/j.20448279.1998.tb01303.x, http://dx.doi.org/10.1111/j.2044-8279.1998.tb01303.x

Hongwei, R. \& Yuying, L. (2011). A Comparison Study on The Rhetorical Moves of Abstracts in Published Research Articles and Master's Foreign-Language Theses. English Language Teaching, 4(1), 162166.

Huckin, T. (2006). Abstracting from abstracts. In M. Hewings (ed.), Academic Writing in Context (pp. 93-103). London: Continuum.

Hyland, K. (2000). Disciplinary Discourses: Social Interactions in Academic Writing. London: Longman.

Kanoksilapatham, B. (2005). Rhetorical studies of biochemistry research articles. English for Specific Purposes, 24, 269-292. http://dx.doi.org/10.1016/j.esp.2004.08.003

Lau, H. H. (2004). The structure of academic journal abstracts written by Taiwanese PhD students. Taiwan Journal of TESOL, 1(1), 1-25.

Lorés, R. (2004). On RA abstracts: from rhetorical structure to thematic organization. English for Specific Purposes, 23, 280-302.

Pho, P. D. (2008). Research article abstracts in applied linguistics and educational technology: a study of linguistic realizations of rhetorical structure and authorial stance. Discourse Studies, 10(2), 231250.http://dx.doi.org/10.1177/1461445607087010

Samraj, Betty. (2008). A discourse analysis of master's theses across disciplines with a focus on introduction. Journal of English for Academic Purposes, 7, 55-67.

Samraj, Betty. (2005). An exploration of a genre set: Research article abstracts and introductions in two disciplines. English for Specific Purposes, 24, 141-156.

Santos, M.B.D. (1996). The textual organization of research paper abstracts in applied linguistics. Text,16, 481-499.

Sidek, H.M., Saad, N.S.M., Baharun, H. \& Idris, M.M. (2016). An analysis of rhetorical moves in abstract in conference proceedings. International e-Journal of Advances in Social Science, 2(4), 24-31.

Swales, J. M. (1990). Genre analysis: English in academic and research settings. Cambridge: Cambridge University Press.

Suntara, W. \& Usaha, S. (2013). Research articles abstracts in two related disciplines: Rhetorical variations between linguistics and applied linguistics. English Language Teaching, 6(2), 84-99.

Stotesbury, H. (2003). Gaps and False Conclusions: Criticism in Research Article Abstracts across the Disciplines. In Ken Hyland, \& Marina Bondi (eds), Academic Discourse Across Disciplines (42, 123148). New York: Peter Lang. 